\title{
Períodos De INTERFerênCIA DE Commelina benghalensis NA Cultura do Café Recém-Plantada ${ }^{1}$
}

\author{
Interference Periods of Commelina benghalensis After Coffee Establishment
}

\author{
DIAS, T.C.S. ${ }^{2}$, ALVES, P.L.C.A. ${ }^{3}$ e LEMES, L.N. ${ }^{4}$
}

\begin{abstract}
RESUMO - A presente pesquisa teve por objetivo avaliar os períodos de interferência de Commelina benghalensis sobre o crescimento inicial de mudas de Coffea arabica, sob condições de inverno e verão. Para isso, mudas de café e, posteriormente, de trapoeraba foram transplantadas para caixas de cimento-amianto com capacidade de $70 \mathrm{~L}$, utilizando solo como substrato. Os períodos de convivência ou controle foram de $0-15,0-30,0-45,0-60$, 0-75 e 0-90 dias após o plantio do cafeeiro, totalizando 12 tratamentos, dispostos em blocos casualizados, em quatro repetições. Ao término de cada período, avaliaram-se algumas características de crescimento das plantas. As características do cafeeiro mais afetadas pela trapoeraba foram a área foliar e a biomassa seca de folhas das mudas de café, sendo essas as únicas características que apresentaram reduções significativas no verão. No inverno, o número de folhas e a biomassa seca do caule também tiveram reduções significativas. Os periodos críticos de prevenção da interferência foram de 15 a 88 e 22 a 38 dias após o plantio das mudas de café, para condições de inverno e verão, respectivamente.
\end{abstract}

Palavras-chave: Coffea arabica, trapoeraba, competição, desenvolvimento.

\begin{abstract}
This research aimed to evaluate the periods of interference of Commelina benghalensis in the initial growth of Coffea arabica seedlings under winter and summer conditions. Coffee seedlings, later followed by spiderwort seedlings, were transplanted into $70 \mathrm{~L}$ cement boxes, using soil as substrate. The control periods were: $0-15,0-30,0-45,0-60$, 0-75 and 0-90 days after coffee sowing, using 12 treatments arranged in a randomized block design, with four replications. At the end of each period, plant height characteristics were evaluated. The coffee plant characteristics most affected by spiderwort were the foliar area and dry biomass of the coffee seedling leaves, under summer conditions. Leaf number and stem dry biomass also suffered significant reductions under winter conditions. The critical periods of interference prevention were 15 to 88 and 22 to 38 days after coffee seedling sowing, under winter and summer conditions, respectively.
\end{abstract}

Key words: Coffea arabica, spiderwort, competition, development.

\section{INTRODUÇÃO}

A cultura do café ocupa posição de destaque na economia brasileira e está intimamente ligada à história do Brasil, como, por exemplo, ao processo de industrialização do Estado de São Paulo. O país colheu na safra 2003/2004 uma área de aproximadamente 2,4 milhões de ha, que produziram 30,743 milhões de sacas (AGRIANUAL, 2005).

\section{Recebido para publicação em 19.3.2004 e na forma revisada em 5.9.2005.}

Eng.-Agr., mestrando em Produção Vegetal, Departamento de Biologia Aplicada à Agropecuária - FCA/UNESP, Via de Acesso Prof. Dr. Paulo D. Castellane, s/n 14884-900 Jaboticabal-SP, <tcsdias@fcav.unesp.br >; ${ }^{3}$ Eng.-Agr., Professor Assistente Doutor do DBAA-FCAV/UNESP, <plalves@fcav.unesp.br>; ${ }^{4}$ Eng.-Agr., mestrando em Produção Vegetal, FCAV/UNESP, $<$ lnlemes@fcav.unesp.br>.

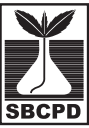


O cafeeiro está sujeito a uma série de fatores que podem afetar o seu desenvolvimento e a sua produção, os quais podem ser abióticos ou bióticos. Dentre os fatores bióticos, destacase a interferência das plantas daninhas sobre as plantas cultivadas em decorrência da competição por luz, nutrientes e água e dos efeitos alelopáticos. Ademais, elas são hospedeiras de pragas e doenças e atrapalham operações como a colheita, as adubações e as aplicações de produtos fitossanitários (Pitelli, 1985).

O grau de interferência de uma planta daninha sobre uma cultura é afetado pela época e duração do período de convivência entre a cultura e as plantas daninhas (Pitelli, 1985). De maneira geral, quanto maior for o período de convivência múltipla - cultura-comunidade infestante -, maior será o grau de interferência. No entanto, esse grau dependerá da época do ciclo da cultura em que esse período for concebido (Pitelli, 1987).

A época, a partir da semeadura ou do plantio, em que a cultura pode conviver com a comunidade infestante, antes que a interferência se instale de maneira definitiva e reduza significativamente a produtividade da lavoura, foi denominada por Pitelli \& Durigan (1984) de periodo anterior à interferência (PAI). Seu limite superior retrata a época em que a interferência compromete irreversivelmente a produtividade econômica da cultura. Esses mesmos autores denominaram de período total de prevenção da interferência (PTPI) o período, a partir da semeadura ou emergência da cultura, durante o qual as plantas daninhas devem ser controladas para que a cultura possa manifestar plenamente seu potencial produtivo. As plantas daninhas que emergirem após esse período não mais causarão reduções na produção.

A interferência imposta pelas plantas daninhas agrava-se quando se trata da cultura em instalação e início de desenvolvimento. Nesses casos, o cafeeiro apresenta um crescimento lento, comparativamente ao das plantas daninhas, sofrendo, portanto, os efeitos da intensa competição pelos recursos do ambiente (Kogan, 1992).

Dentre as plantas infestantes da cultura do café, destaca-se a trapoeraba (Commelina benghalensis), não só pelo seu difícil controle, mas também pela sua agressividade. Esta planta daninha vem sendo selecionada em áreas com aplicação do herbicida glifosato de forma isolada (Ramos \& Durigan, 1996) e pode causar grande redução no desenvolvimento do cafeeiro (Dias et al., 2001; Ronchi et al., 2003), principalmente quando jovem (Ronchi et al., 2001) .

Dessa forma, a presente pesquisa objetivou avaliar o efeito de períodos de controle e de convivência de $C$. benghalensis sobre o crescimento inicial de mudas de café, em condições de inverno e verão.

\section{MATERIAL E MÉTODOS}

Os experimentos foram realizados em condições semicontroladas (em ambiente aberto, mas com irrigações periódicas complementares), com mudas de Coffea arabica cv. Catuaí Vermelho (IAC 144), sob duas condições climáticas, no município de Jaboticabal, SP, Brasil (situado em uma latitude de $21^{\circ} 15^{\prime} 22^{\prime}$ " sul e longitude de $48^{\circ} 18^{\prime} 58^{\prime \prime}$ oeste). Nas condições de inverno (abril, maio e junho de 2002), teve-se a temperatura máxima de $29,8^{\circ} \mathrm{C}$, temperatura minima de $16,1^{\circ} \mathrm{C}$, umidade relativa média de 67,5\%, 266 horas de insolação e 50,8 mm de precipitação acumulada; e nas condições de verão (dezembro de 2002, janeiro e fevereiro de 2003), a temperatura máxima foi de $31,4^{\circ} \mathrm{C}$, temperatura mínima de $20,5{ }^{\circ} \mathrm{C}$, umidade relativa média de 79,2\%, 202 horas de insolação e 768 mm de precipitação acumulada.

Os experimentos foram instalados em caixas de cimento-amianto com capacidade para $75 \mathrm{~L}(0,50 \times 0,50 \times 0,30 \mathrm{~m})$, utilizando-se como substrato solo coletado na camada arável de um Latossolo Vermelho de textura média, cujas caracteristicas químicas foram: $\mathrm{pH}$ em $\mathrm{CaCl}_{2}$ de 4,7; $20 \mathrm{~g} \mathrm{dm}^{-3}$ de matéria orgânica; $23 \mathrm{mg} \mathrm{dm}^{-3}$ de P (resina); 5,0, 20, 7, 38, 32 e $70 \mathrm{mmol} \mathrm{dm}^{-3} \mathrm{de} \mathrm{K}, \mathrm{Ca}, \mathrm{Mg}, \mathrm{H}+\mathrm{Al}$ e $\mathrm{SB}$, respectivamente; e V\% de 46. Trinta dias antes do plantio das mudas de café, foram adicionados a cada caixa $200 \mathrm{~g}$ de superfosfato simples e $5 \mathrm{~L}$ de esterco de curral curtido. Aos 30 e 60 dias após o plantio, as plantas de café foram adubadas com 4,5 g de uréia. Por ocasião do plantio das mudas no verão, estas se encontravam com, em média, três pares de folhas; no 
inverno, elas se encontravam com cinco pares de folhas.

As mudas de trapoeraba foram coletadas em área de significativa infestação, quando se apresentavam no estádio de três a cinco folhas. Logo após, três ou duas mudas - para inverno ou verão, respectivamente - foram plantadas nas caixas, juntamente com uma única muda de café, de acordo com cada tratamento (período). As densidades utilizadas foram estipuladas seguindo levantamentos prévios feitos em área de produção comercial de café, em Arceburgo-MG.

O delineamento experimental utilizado, para os dois experimentos, foi o em blocos casualizados, com quatro repetições. Os tratamentos experimentais foram constituídos de seis periodos crescentes de convivência ou controle da trapoeraba, considerados a partir do plantio do café. Eles foram separados em dois grupos: convivência, para os períodos iniciais de convivência com as plantas daninhas; e controle, para os períodos iniciais de controle. Os periodos de convivência ou controle foram de 15, 30, 45, 60, 75 e 90 dias após o plantio das mudas de café. No final de cada período, as plantas daninhas foram removidas e postas para secar em estufa com circulação forçada de ar, a $70{ }^{\circ} \mathrm{C}$ por 96 horas, sendo posteriormente pesadas em balança com precisão de $0,01 \mathrm{~g}$.

Aos 90 dias após o plantio (DAP) das mudas de café, foram medidos a altura das plantas, o diâmetro do caule, o número de folhas, a matéria seca de caule e folhas e a área foliar, por meio de um medidor de área foliar (Li-Cor Instruments, modelo LI-3000A). O diâmetro do caule foi obtido por medições na região do colo, e a altura das plantas, pelo comprimento do caule. Para obtenção da massa do caule seca e das folhas secas do cafeeiro, seguiu-se o mesmo procedimento adotado para determinação da massa da trapoeraba seca.

Os resultados relativos a cada caracteristica avaliada no cafeeiro foram submetidos à análise de variância pelo teste $\mathrm{F}$, com as médias sendo comparadas com o teste de Tukey a 5\% de probabilidade. Esses resultados foram, ainda, expressos percentualmente em relação à testemunha mantida no limpo no decorrer do período experimental e, posteriormente, processados separadamente dentro de cada grupo (controle ou convivência), sendo submetidos à análise de regressão pelo modelo sigmoidal de Boltzman (Origin, versão 6.1), segundo proposição de Kuva et al. (2000). Para determinar os períodos de interferência, considerou-se uma redução de $5 \%$ nas características das mudas de café que foram afetadas pelas plantas de trapoeraba.

\section{RESULTADOS E DISCUSSÃO}

Sob condições de inverno, a massa da parte aérea das plantas de trapoeraba secas aumentou com o incremento dos períodos de convivência até 60 DAP, quando acumulou $60,4 \mathrm{~g}$, estabilizando-se até os 90 DAP. Nos períodos de controle, a massa da planta daninha seca ficou estável até os 30 DAP, quando apresentou acúmulo de 58,0 g, decrescendo a partir desta época, com o aumento do período de controle (Figura 1).

A trapoeraba afetou negativamente o número de folhas do cafeeiro, uma vez que, após a convivência da muda de café com a trapoeraba por 90 dias, verificou-se redução de 18,9\% em relação à parcela que ficou completamente livre das plantas daninhas. Da mesma forma, as plantas de café que permaneceram por 15 dias no limpo, ou seja, 75 dias "no mato", apresentaram redução no número de folhas de $29,7 \%$ quando comparadas com aquelas que permaneceram apenas 15 dias "no mato" (Figura 2A).

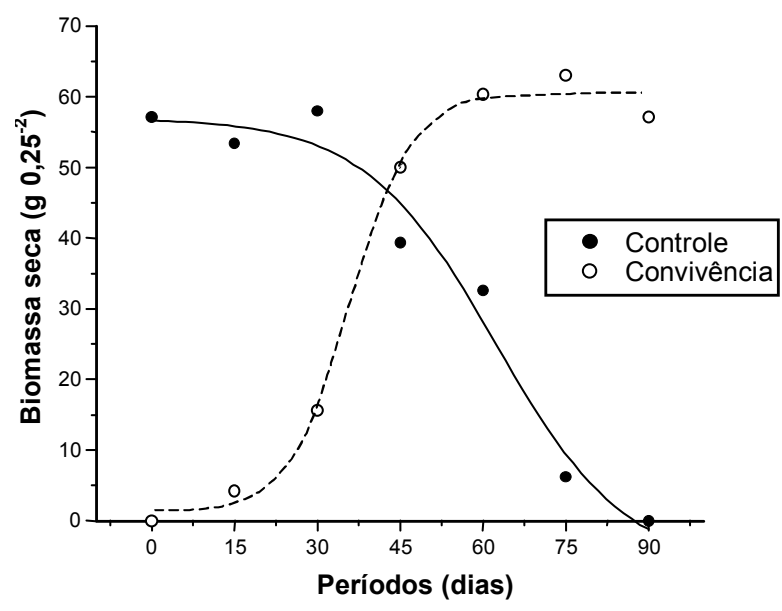

Figura 1 - Massa da parte aérea da trapoeraba seca, para os períodos de controle e convivência no inverno.

Planta Daninha, Viçosa-MG, v. 23, n. 3, p. 397-404, 2005 
A massa das folhas das plantas de café seca reduziu significativamente no tratamento em que houve convivência da planta de trapoeraba com o cafeeiro por 90 dias, em relação ao tratamento em que a trapoeraba foi controlada nesse mesmo período - essa redução foi de 51,1\% (Figura $2 \mathrm{~B}$ ).

A área foliar do cafeeiro foi a característica mais influenciada pela interferência das plantas de trapoeraba (Figura 3A). Nas plantas em que se controlou a planta daninha por 90 dias a área foliar foi de $1.443 \mathrm{~cm}^{2}$, enquanto nas plantas da parcela em que houve convivência entre as duas espécies por esse mesmo período a área foliar foi de apenas
$673 \mathrm{~cm}^{2}(-53,4 \%)$. Nos períodos de convivência entre a cultura e a planta daninha, a partir dos 30 dias, constatou-se redução significativa na área foliar do cafeeiro; já para os períodos de controle ocorreu redução nessa característica quando este conviveu com a trapoeraba dos 0 aos 45 DAP.

Na massa do caule seca ocorreu diferença apenas entre as plantas com controle da planta de trapoeraba por 90 dias e aquelas sem controle pelo mesmo período. A redução observada foi de $44,8 \%$ para as plantas que conviveram com a planta daninha. A altura e o diâmetro do caule das mudas de café não foram afetados pelas plantas de trapoeraba até os 90 DAP.
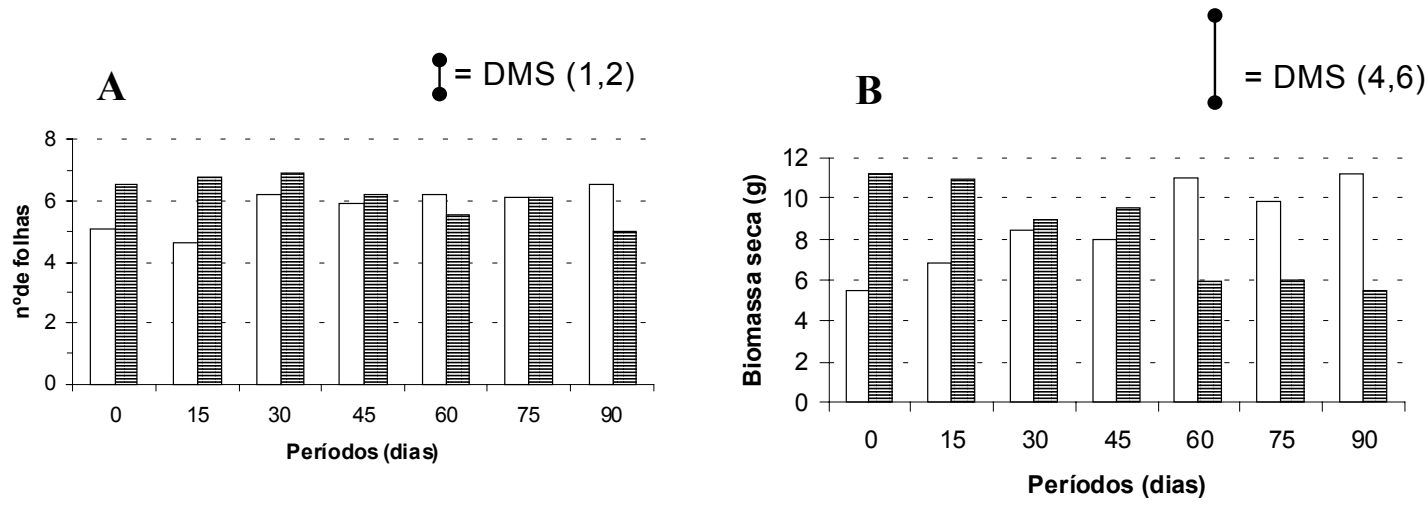

controle

convivência

Figura 2 - Número de folhas (A) e massa das folhas seca (B) do cafeeiro, aos 90 DAT, em função dos períodos de controle e de convivência, em condições de inverno.
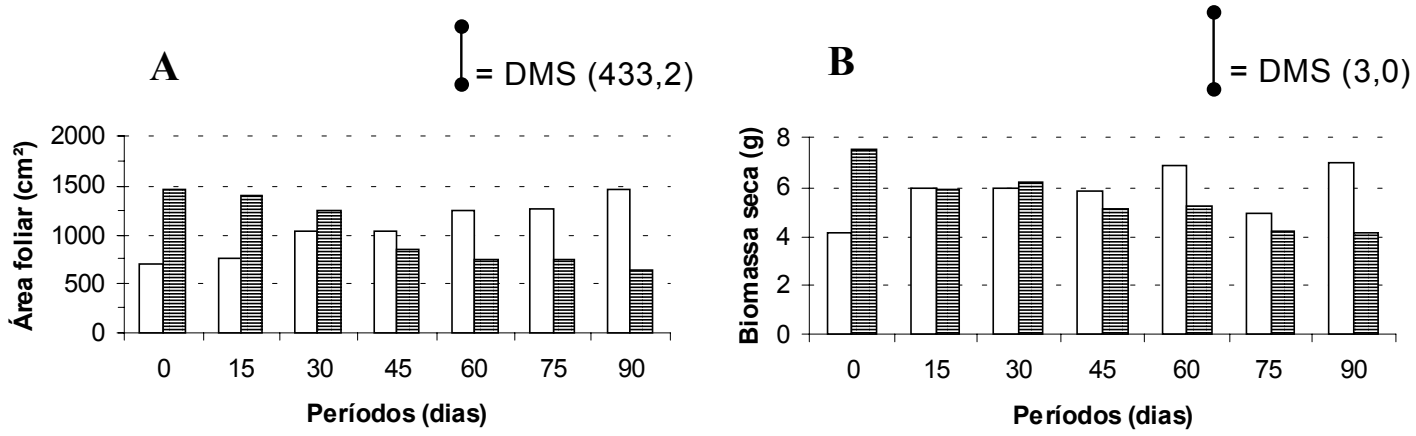

controle

convivência

Figura 3 - Área foliar (A) e massa do caule seca (B) do cafeeiro aos 90 DAT, em função dos períodos de controle e de convivência, em condições de inverno.

Planta Daninha, Viçosa-MG, v. 23, n. 3, p. 397-404, 2005

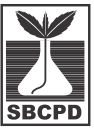


O PAI das plantas de trapoeraba sob condições de inverno foi de 15 DAP, enquanto o PTPI foi de 88 DAP. Dessa forma, o PCPI das plantas de trapoeraba no cafeeiro foi dos 15 aos 88 DAP (Figura 4).

No ensaio sob condições de verão, a massa da parte aérea das plantas de trapoeraba seca apresentou lento crescimento até os 45 dias de convivência, quando atingiu 32,0 g. Entre 45 e 60 dias houve grande acúmulo de massa das plantas de trapoeraba seca, atingindo $126,0 \mathrm{~g}$. Aos 90 dias de convivência, as plantas acumularam 151,8 g de matéria seca (Figura $5)$. Nos períodos de controle, a massa da trapoeraba seca foi decrescente com o aumento do período sem a presença da planta daninha. Sua queda mais acentuada foi entre 15 e 60 DAP. Entre 0 e 15 e 60 e 90 DAP, as plantas apresentaram pouca variação no acúmulo de biomassa; aquelas plantadas após os 90 dias acumularam pouca biomassa seca.

Decorridos 90 dias do plantio das mudas de café, as plantas de trapoeraba não interferiram no número de folhas do cafeeiro, em nenhum dos períodos de controle e de convivência das plantas. Contudo, a área foliar do cafeeiro foi a característica mais prejudicada pela trapoeraba (Figura 6A). O cafeeiro que permaneceu por 90 dias sob a presença da planta daninha apresentou área foliar de $418 \mathrm{~cm}^{2}$, contra $728 \mathrm{~cm}^{2}$ daquela que ficou por 90 dias sem esta planta, redução essa de $52 \%$. A redução na área foliar do cafeeiro manifestou-se a partir dos 60 dias de convivência com as plantas de trapoeraba, mas foi necessário um período de 15 dias após o plantio para que não ocorresse redução nessa característica. A massa das folhas de café seca teve redução significativa, uma vez que as plantas que permaneceram na presença da planta daninha, por 90 dias, apresentaram massa seca de 2,10 g, representando redução de 30\% em relação àquelas da parcela que permaneceu livre das plantas de trapoeraba por 90 dias (Figura 6B). Foram necessários mais de 45 dias de convivência entre as plantas para que ocorresse redução na matéria seca das folhas do cafeeiro e um período inicial de 15 dias no limpo para que não ocorresse efeito negativo sobre essa característica.

O efeito da densidade de trapoeraba sobre o crescimento inicial do cafeeiro chegou a reduzir em 59\% a massa das folhas seca e em $56 \%$ a área foliar do cafeeiro, a partir da densidade de 8 plantas $\mathrm{m}^{-2}$ (DIAS et al., 2001). A massa do caule seca do cafeeiro não foi afetada pelas plantas de trapoeraba em nenhum dos períodos de controle e de convivência. Tanto para as plantas que ficaram livres da presença da trapoeraba por 90 dias como para as que conviveram com ela por esse mesmo tempo, a biomassa seca do caule foi de 1,62 g.

Para diâmetro e biomassa seca do caule e altura das plantas de café, a convivência entre a cultura e a planta daninha, mesmo

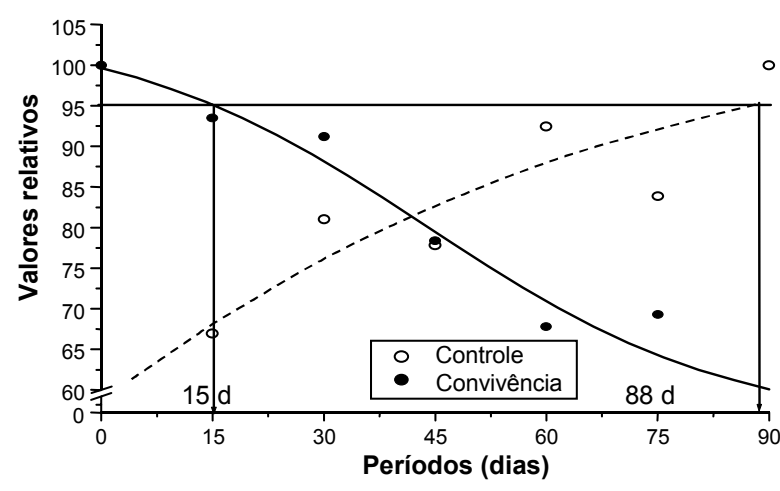

Figura 4 - Efeitos dos períodos de controle e de convivência das plantas de trapoeraba sobre o crescimento de mudas de café sob condições de inverno. Médias de efeitos sobre número de folhas, área foliar, matéria seca de folhas e de caule. Valores relativos à testemunha no limpo.

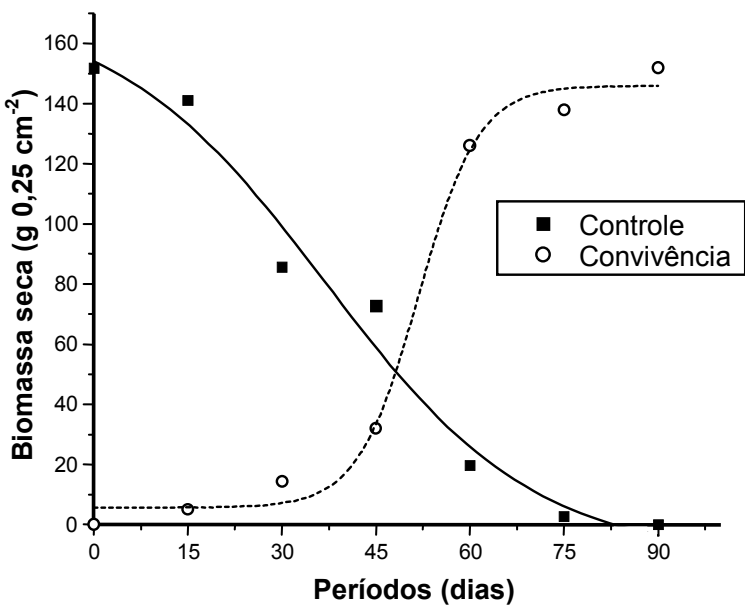

Figura 5 - Massa da parte aérea da trapoeraba seca, aos 90 DAT, em função dos períodos de controle e convivência, em condições de verão.

Planta Daninha, Viçosa-MG, v. 23, n. 3, p. 397-404, 2005 


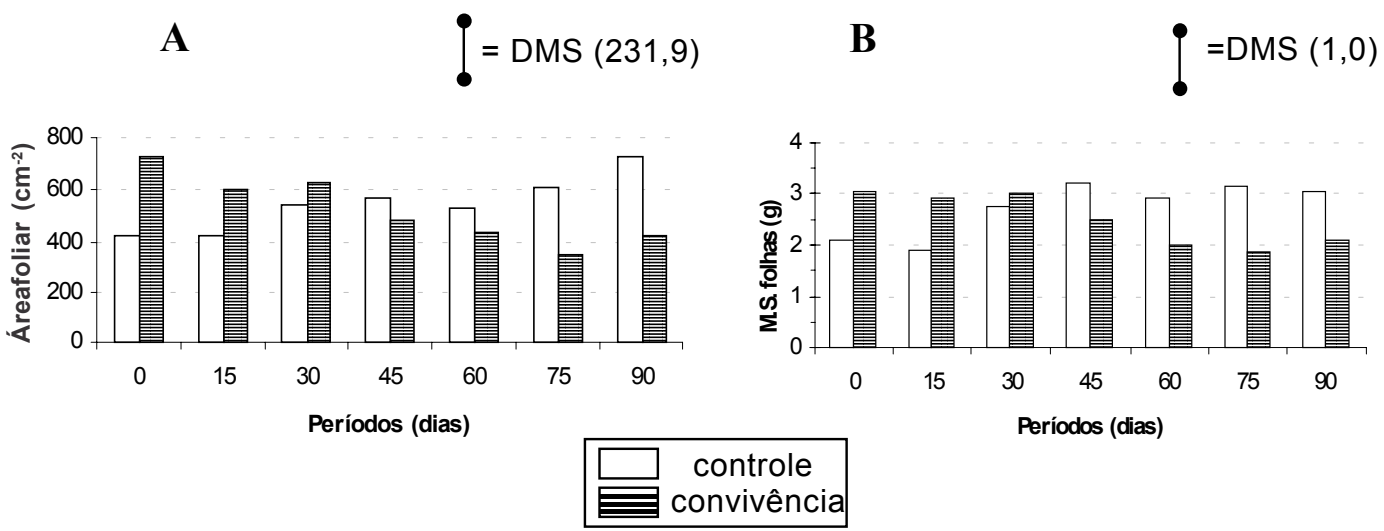

Figura 6 - Área foliar (A) e massa das folhas seca (B) do cafeeiro, aos 90 DAT, em função dos períodos de controle e convivência, em condições de verão.

por 90 dias, não causou redução nessas características (dados não apresentados). Tanto sob condições de inverno como de verão, essas foram as características menos influenciadas pela planta daninha. O cafeeiro é uma planta que naturalmente apresenta um crescimento inicial lento; portanto, respostas na altura das plantas só seriam mais evidentes com períodos de convivência maior. A altura do cafeeiro foi a característica menos sensivel à interferência de Brachiaria decumbens (DIAS et al., 2004)

O PAI das plantas de trapoeraba sob condições de verão foi de 21 dias, e o PTPI, de 38 dias. Dessa forma, o PCPI das plantas de trapoeraba no cafeeiro foi dos 21 aos 38 dias após o plantio das mudas (Figura 7).

No cafeeiro Mundo Novo, um ano após a recepa, na época das águas (outubro a março), para uma população com predominância de Digitaria horizontalis, Brachiaria plantaginea e Parthenium hysterophorus, o PAI foi de 86 dias na primeira safra e 138 na segunda. As plantas daninhas que conviveram com a cultura durante toda a época de chuvas reduziram a produção da cultura em 53 e 47\% na primeira e segunda safras, respectivamente (LEMES et al., 2003).

Observou-se o maior desenvolvimento da trapoeraba sob condições de verão, periodo esse com temperaturas médias mais elevadas, maior umidade relativa, irradiância e precipitação, o que está de acordo com Kissmann (1997). Embora os experimentos tenham sido conduzidos com complementação de água por meio de irrigações periódicas, verificou-se que no inverno os fatores limitantes foram os periodos de baixa umidade relativa, associada a baixas temperaturas, o que provavelmente resultou em baixa disponibilidade de água no substrato.

Mesmo com o maior desenvolvimento da trapoeraba no período do verão, os efeitos mais significativos da planta daninha sobre o desenvolvimento do cafeeiro foram observados no inverno, provavelmente em decorrência dos fatores limitantes mencionados anteriormente, demonstrando que nessas condições o cafeeiro tornou-se menos competitivo que a planta daninha.

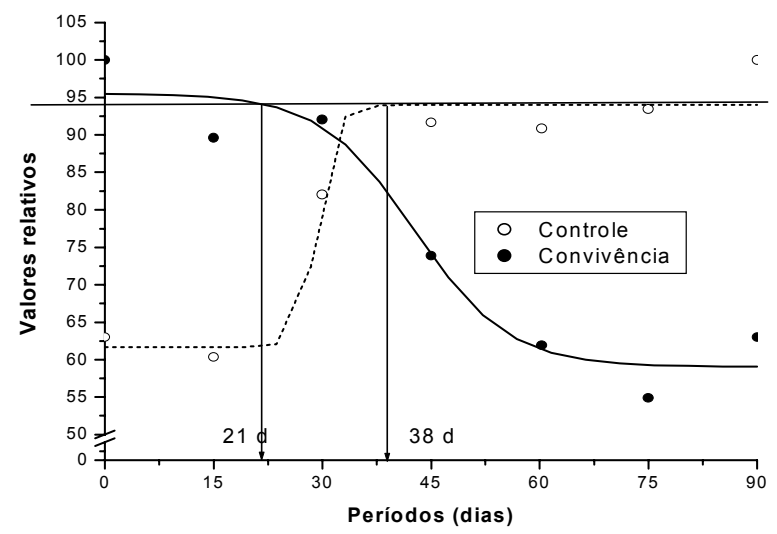

Figura 7 - Efeitos dos períodos de controle e de convivência das plantas de trapoeraba sobre o crescimento de mudas de café sob condições de verão. Médias de efeitos sobre área foliar e matéria seca de folhas. Valores relativos à testemunha no limpo. 
No inverno, foi necessário que as mudas de café ficassem por um maior período livre da presença da infestante, além de o cafeeiro ter sofrido maiores reduções nas características avaliadas nesse mesmo período. Esse comportamento se assemelha ao observado por Costa et al. (2004), os quais, estudando os períodos de interferência da trapoeraba sobre o crescimento inicial de Eucalyptus grandis (outra espécie perene) sob condições de inverno e verão, determinaram que no inverno o PCPI foi dos 20 aos 60 DAP e que, no verão, o PAI foi de 40 DAP e o PTPI, de 10 DAP. Isso significa que nessas condições, assim como o cafeeiro, o eucalipto foi mais prejudicado pela planta daninha.

Segundo Ronchi et al. (2001), como tanto a cultura como as plantas daninhas possuem demandas por água, luz, nutrientes e $\mathrm{CO}_{2}$ e, na maioria das vezes, esses fatores de crescimento (ou pelo menos um deles) estão disponíveis em quantidade insuficiente, estabelece-se assim a competição. É de se esperar que, quanto menor for a disponibilidade de água, não só no solo, mas também no ar, como ocorreu no experimento sob condições de inverno, mais prejudicial será o efeito da planta daninha sobre o cafeeiro, não só pela competição por água, como também por nutrientes, já que sua absorção depende da quantidade de água disponivel no solo.

Friessleben et al. (1991) demonstraram que o controle das plantas daninhas durante o período seco foi mais importante em reduzir os efeitos da competição do que durante o período chuvoso. Esses autores concluíram que durante o período seco existem condições favoráveis para o desenvolvimento de uma flora de plantas daninhas que irá interferir nas plantas de café pela competição por água.

Há um excesso de disponibilidade de água de chuva sobre a transpiração do cafeeiro nos meses que vão de outubro a março. Em abril, junho e setembro, essa disponibilidade é menor; em maio, julho e agosto há, em média, deficiência de água, isto é, a transpiração excede a queda pluviométrica (Franco \& Inforzato, 1950). Existe ainda a possibilidade de as plantas de trapoeraba, por serem mais eficientes fotossinteticamente que o cafeeiro (Holm et al., 1977), terem se tornado mais agressivas que a cultura em resposta aos diferentes períodos de insolação entre inverno e verão.

Segundo Kogan (1992), o período crítico de interferência das plantas daninhas em culturas perenes é na fase inicial da implantação, motivo pelo qual este trabalho foi conduzido por 90 dias. Contudo, os resultados aqui obtidos demonstram que em uma área infestada por plantas daninhas com predominância de trapoeraba há um período em que se pode permitir a convivência com essas plantas sem que haja prejuízos à cultura, cuja duração vai depender da época de seu plantio, permitindo, inclusive, melhor aproveitamento do período residual de herbicidas pré e pós-emergentes, pelo atraso na sua aplicação em função desse período.

Pelos resultados obtidos no ensaio, conclui-se que sob condições de inverno C. benghalensis na densidade de 12 plantas $\mathrm{m}^{-2}$ reduz o número de folhas, a área foliar e a matéria seca de caule e folhas do cafeeiro. Sob essa condição, o PCPI é dos 15 aos 88 DAP das mudas de café. Sob condições de verão, a trapoeraba na densidade de 8 plantas $\mathrm{m}^{-2}$ reduz a área foliar e matéria seca de folhas do cafeeiro, sendo o PCPI dos 21 aos 38 DAP.

\section{AGRADECIMENTO}

Ao CNPq, pela concessão de bolsa de iniciação científica ao primeiro autor para realização deste trabalho.

\section{LITERATURA CITADA}

AGRIANUAL: Anuário da agricultura brasileira. São Paulo: FNP Consultoria e Agroinformativos, 2005. p. 241-250.

COSTA, A. G. F.; ALVES, P. L. C. A.; PAVANI, M. C. M. D. Períodos de interferência de trapoeraba (Commelina benghalensis) no crescimento inicial de eucalipto (Eucalyptus grandis). R. Árvore, v. 28, n. 4, p. 471-478, 2004.

DIAS, G. F. S.; ALVES, P. L. C. A.; DIAS, T. C. S. Brachiaria decumbens suppresses the initial growth of coffee. Sci. Agric., v. 61, n. 6, p. 579-583, 2004.

DIAS, T. C. S. et al. Efeito da densidade de trapoeraba sobre o crescimento inicial do cafeeiro. In: CONGRESSO DE INICIAÇÃO CIENTÍFICA DA UNESP, 13., 2001, Bauru. Anais... Bauru: UNESP, 2001. p. 271.

FRANCO, C. M.; INFORZATO, R. Quantidade de água transpirada pelo cafeeiro cultivado ao sol. Bragantia, v. 10, n. 9 , p. $247-257,1950$.

Planta Daninha, Viçosa-MG, v. 23, n. 3, p. 397-404, 2005 
FRIESSLEBEN, U.; POHLAN, J.; FRANKE, G. The response of Coffea arabica L. to weed competition. Café Cacao Thé, v. 25, p. 15-20, 1991.

HOLM, L. G. et al. The world's worst weeds. Honolulu: University Press of Hawaii, 1977. 607 p.

KISSMANN, K. G. Plantas infestantes e nocivas. São Paulo: BASF Brasileira, 1997. p. 98-102.

KOGAN, M. A. Interferencia de las malezas en plantaciones y estrategias de control. In: AVANCES en manejo de malezas en producción agrícola y forestal. Santiago: Pontifícia Universidad Católica, 1992. p. 119.

KUVA, M. A.; PITELLI, R A.; CHRISTOFFOLETI, P. J. Período de interferência das plantas daninhas na cultura da cana-de-açúcar. I-Tiririca. Planta Daninha, v. 18, n. 2, p. 241-251, 2000.

LEMES, L. N.; ALVES, P. L. C. A.; DIAS, T. C. S Determinação do período anterior à interferência das plantas daninhas na produção do cafeeiro "Mundo Novo" recepado In: CONGRESO LATINOAMERICANO DE MALEZAS (ALAM), 16., 2003, Manzanilo. Resumos... Manzilo: Universidad de Colima, 2003. p. 446.

PITELLI, R. A. Interferência das plantas daninhas nas culturas agrícolas. Inf. Agropec., v. 11, n. 29, p. 16-27, 1985.
PITELLI, R. A. Competição e controle de plantas daninhas em áreas agrícolas. IPEF, v. 4, n. 12, p. 25-35, 1987.

PITELLI, R. A.; DURIGAN, J. C. Terminologia para períodos de controle e de convivência das plantas daninhas em culturas anuais e bianuais. In: CONGRESSO BRASILEIRO DE HERBICIDAS E PLANTAS DANINHAS, 15., 1984, Belo Horizonte. Resumos... Belo Horizonte: SBHED, 1984. p. 37.

PITELLI, R. A.; MARCHI, S. R. Interferência das plantas invasoras nas áreas de reflorestamento. In: SEMINÁRIO TÉCNICO SOBRE PLANTAS DANINHAS E O USO DE HERBICIDAS EM REFLORESTAMENTO, 3., 1991, Belo Horizonte. Anais... Belo Horizonte: 1991. p. 1-11.

RAMOS, H. H.; DURIGAN, J. C. Avaliação da eficiência da mistura pronta de glyphosate $+2,4-D$ no controle da Commelina virginica L. em citros. Planta Daninha, v. 14, n. 1, p. 33-41, 1996.

RONCHI, P. R.; DA SILVA; A. A.; FERREIRA, L. R. Manejo de plantas daninhas em lavouras de café. Viçosa-MG: Suprema Gráfica e Editora, 2001. 94 p.

RONCHI, C. P. et al. Acúmulo de nutrientes pelo cafeeiro sob interferência de plantas daninhas. Planta Daninha, v. 21, n. 2 , p. $219-227,2003$. 